Revue de l'Institut des langues et cultures

d'Europe, Amérique, Afrique, Asie et Australie

$33 \mid 2018$

Femmes en résistance du XVIIIe siècle à nos jours

\title{
Resistencias femeninas en el antifranquismo, Zaragoza (1965-1975)
}

Women's Resistance of the Anti Francoism, Zaragoza (1965-1975)

Les résistances des femmes dans l'antifranquisme, Saragosse (1965-1975)

\section{Sandra Blasco Lisa}

\section{(2) OpenEdition}

\section{Journals}

Edición electrónica

URL: http://journals.openedition.org/ilcea/5240

DOI: $10.4000 /$ ilcea.5240

ISSN: 2101-0609

Editor

UGA Éditions/Université Grenoble Alpes

\section{Edición impresa}

ISBN: 978-2-37747-060-0

ISSN: 1639-6073

\section{Referencia electrónica}

Sandra Blasco Lisa, «Resistencias femeninas en el antifranquismo, Zaragoza (1965-1975) », ILCEA [En línea], 33 | 2018, Publicado el 05 noviembre 2018, consultado el 20 abril 2019. URL : http:// journals.openedition.org/ilcea/5240 ; DOI : 10.4000/ilcea.5240

Este documento fue generado automáticamente el 20 abril 2019.

(C) ILCEA 


\title{
Resistencias femeninas en el antifranquismo, Zaragoza (1965-1975)
}

Women's Resistance of the Anti Francoism, Zaragoza (1965-1975) Les résistances des femmes dans l'antifranquisme, Saragosse (1965-1975)

\author{
Sandra Blasco Lisa
}

\section{Introducción}

1 La presión popular ejercida por una parte de la ciudadanía en España en los años sesenta y setenta fue de suma importancia para que se produjese el cambio de régimen del franquismo a la democracia. Por ello, tenemos que investigar a aquellos grupos que hicieron posible este proceso, o lo que es lo mismo, indagar en esa heterogénea composición del antifranquismo que, desde los años sesenta, empezó a formular posibilidades políticas nuevas, a demoler un régimen denostado y a plantear espacios alternativos «desde abajo» donde poder poner en práctica una primigenia teoría democr ática. Esta amalgama de personas y espacios, en definitiva, estas redes, fueron multidireccionales. Hubo experiencias y emociones vividas por las mismas personas en varios contextos de resistencia y esta colosal implicación de la militancia fue la que posibilitó crear un movimiento eficaz de presión contra el Régimen.

2 Historiográficamente, las resistencias femeninas al franquismo no tuvieron inicialmente un campo específico de estudio. Las primeras obras publicadas al respecto fueron escritas por las propias militantes represaliadas desde sus experiencias personales contra Franco. La obra de Giuliana Di Febo, publicada en 1979 y que se consagró como la obra de referencia en la historiografía, Resistencia y movimiento de mujeres en España 1936-1976, fue pionera en su estudio y propuso una categoría de análisis, «mujer de preso», que ha sido fundamental en los estudios sobre las resistencias femeninas al franquismo. Para Di Febo, la figura de la mujer de preso denota una «función política» contra Franco, como símbolo 
y testimonio de la represión (Di Febo, 1979). Posteriormente, diversas investigaciones, como las de Irene Abad o Francisco Arriero, han analizado la participación de las militantes del PCE así como las iniciativas feministas en el Movimiento Democrático de Mujeres (MDM) valiéndose de esta categoría (Abad, 2012; Arriero, 2016). De igual forma, siguen estando vigentes las aportaciones de Di Febo en cuanto a los cambios acontecidos en los años sesenta en España y que abrieron posibilidades nuevas a las resistencias contra Franco desde la vida cotidiana, en las fábricas y en los barrios de las grandes ciudades. Actualmente, estos postulados los encontramos en diversos estudios de historia local que nos permiten conocer las resistencias femeninas en perspectiva comparada (Fernández, 2009; Cabrero, 2016). Además, se complementan con aquellos que trabajan los inicios del movimiento feminista, entre los cuales el libro de Amparo Moreno Mujeres en lucha (1977) es la principal referencia. La autora presta atención a los feminismos de los años sesenta y primeros setenta diferenciando a las militantes del MDM con las militantes feministas independientes y además hace un balance de las diferentes tendencias del feminismo que surgen desde 1975. La obra siendo hoy de una enorme utilidad para estudiar el feminismo de segunda ola en España.

3 Este artículo cubre un vacío historiográfico importante. Aragón, para el conjunto del territorio nacional, fue uno de los casos paradigmáticos del desarrollismo industrial, de la inmigración del campo a la ciudad, de la segregación de clase y de la masificación urbana en los suburbios periféricos de las grandes ciudades. En los años cincuenta, el Régimen franquista se consolida, se abre al exterior y, aprovechando la situación internacional de Guerra Fría marcada por un fuerte anticomunismo, se acerca a EEUU e ingresa en el Fondo Monetario Internacional (FMI) y en la Organización de Naciones Unidas (ONU). De forma paralela, se produce una progresiva liberalización económica gracias al gobierno tecnócrata de 1957 y el Plan de Estabilización de 1959. Esta política tuvo tres principales consecuencias para Aragón: la concentración de numerosas empresas del sector industrial en Zaragoza, la llegada de una oleada migrante que se instaló en los barrios periféricos de la ciudad y un mayor acceso al mercado laboral del sector femenino favorecido por unas políticas económicas flexibles en la contratación de mano de obra barata. Consecuentemente, Zaragoza fue una ciudad con una enorme conflictividad obrera y estudiantil y con un movimiento ciudadano muy potente debido a la creación de unos barrios que carecían de condiciones para una vida digna.

4 En este contexto de movilizaciones, encontramos resistencias específicas de mujeres que supusieron una acción contra la Dictadura y contra el modelo de género vigente. Precisamente, es el análisis de este contexto y de los significados atribuidos a esa experiencia contra el Régimen lo que nos permite arrojar luz sobre las reivindicaciones que nacieron desde la experiencia cotidiana, construida históricamente a partir de nociones de diferencia sexual y de roles diferenciados para hombres y mujeres. Esta visión, junto a la revisión de los feminismos históricos efectuada para la historiografía europea y española, nos permite dar mayor complejidad y rigor a las investigaciones así como ser consecuentes con la interpretación, desde el uso del género como categoría útil para el análisis histórico, y desde el conocimiento del mismo como fruto de unas coordenadas específicas (Nash, 1994).

5 Las actitudes de insumisión de las mujeres de preso o de las amas de casa pidiendo mejoras para sus familiares, en los barrios o la militancia en los partidos clandestinos suponían una transgresión de la lógica sexual del régimen de Franco (o Dictadura de Franco). Lo público para el sistema sexo-género franquista se reducía al ámbito de «lo 
masculino», por ello, el activismo llevado a cabo por estas luchadoras contra Franco trasgredía el rol impuesto. Además, como se demuestra en este artículo, para las militantes es una trasgresión consciente, una trasgresión compartida en todos los contextos en los que se conforman resistencias de mujeres contra Franco. Esta consciencia les lleva a hablar desde un sujeto propio y a cuestionar la subordinación de las mujeres tanto en la sociedad como entre los propios militantes creando para ello organizaciones específicas dentro del antifranquismo.

\section{«De la amnistía al feminismo»: las mujeres del Partido Comunista de España y el Movimiento Democrático de Mujeres}

6 Hablar de resistencias femeninas al franquismo en los años sesenta nos obliga a hacer referencia a las mujeres del Partido Comunista de España. Fue el partido que por antonomasia luchó contra Franco. De entre sus militantes muchas sufrieron en sus cuerpos el estigma de la represión, como el exilio, la cárcel o el fusilamiento.

Muchas de ellas además eran madres, hermanas, esposas o hijas de presos políticos, muchas debían hacer cola extramuros de las cárceles franquistas para visitar y llevar ropa y comida a sus familiares, solicitaban apoyos económicos y denunciaban los abusos que sufrían los presos. Todas ellas tenían el estigma de pertenecer a una familia de los vencidos en la Guerra Civil.

8 La figura de la mujer de preso nace de cómo una experiencia personal se transformó en una identidad colectiva entre aquellas mujeres que tenían familiares presos. Esto les llevó a organizarse y comprometerse públicamente contra la Dictadura. Entre las acciones de resistencia protagonizadas por las mujeres del PCE destacaron la recogida de firmas contra las torturas y los malos tratos en las cárceles, la petición de indultos para los presos, escribir y tirar octavillas reclamando la amnistía... De estas dos dinámicas, la denuncia de la represión y la movilización de las mujeres de preso, surgió el Movimiento Democrático de Mujeres (MDM). La iniciativa del MDM surgió en Madrid a partir de tres experiencias colectivas. En primer lugar, una huelga en la Puerta del Sol en protesta por la represión de las mujeres asturianas en 1962. En segundo lugar, las reuniones de mujeres de preso donde se trataban los temas de ayuda mutua, solidaridad y amnistía. En tercer lugar, algunas universitarias (entre las que se encontraban Manuela Carmena, actual alcaldesa de Madrid, y Cristina Almeida) y algunas mujeres de preso comenzaron un taller de lectura feminista (Arriero, 2016).

9 El objetivo era crear una organización a nivel estatal, un movimiento, que debía ser interclasista y plural, «de masas», que lograse llegar a los barrios con más necesidad, fomentase una toma de conciencia a partir de la carestía de vida y que tejiese lazos de solidaridad con la situación de los presos políticos. Además debía servir para debatir la posición de las comunistas en el PCE y la situación de las mujeres en la sociedad.

A veces nos reunimos en casa de un camarada casado. Él milita, es activo, le preguntas: ¿Y tu mujer es del partido? Y contesta ¡Ah no!, ¿Qué impide que sea ella del Partido si tienen todas las condiciones de serlo? Ahí está la cuestión: ella ha de quedar en casa, con todo el peso de las tareas domesticas. Él milita. Es un problema de educación, pero lo es (Arriero, 2016: 35). 
10 Junto a Madrid, los otros tres grupos pioneros del MDM fueron Asturias, Galicia y Aragón. Algunas mujeres zaragozanas como Teresa Gil ${ }^{1}$, Maruja Cazcarra ${ }^{2}$ o Victoria Martínez ${ }^{3}$ eran hermanas y esposa, respectivamente, de presos políticos del Penal de Burgos. Ellas tres se acompañaban en los trayectos Zaragoza-Burgos, incluso llegaron a alquilar un piso compartido, para poder visitar a sus familiares. Fueron al arzobispado de Burgos, al gobernador civil y escribieron a diversos periódicos de la ciudad denunciando las malas condiciones en las que cumplían condena sus familiares.

Burgos se convirtió en el centro neurálgico de la movilización femenina en pro de los presos políticos. Todas aquellas que acudían desde otras ciudades o pueblos españoles confluían en la barriada Yagüe, típicamente obrera y donde muchas familias alquilaban habitaciones con derecho a cocina a los familiares que acudían de visita al penal (Abad, 2006: 19).

11 Tras el traslado de los presos a la cárcel de Torrero, en Zaragoza, crearon en 1966 una red de apoyo de las mujeres de preso y algunas católicas de base. Entre ellas, Concha Reblet ${ }^{4}$, Teresa Gil, Maruja Cazcarra, Victoria Martínez o Esperanza Martínez fueron algunas de las primeras integrantes en Zaragoza.

Esperanza Martínez fue guerrillera de la Agrupación del Levante y Aragón (A.G.L.A) a finales de los años cuarenta. Juzgada y condenada a veinte años de prisión, cumplió condena en el Penal de Burgos hasta finales de los años sesenta. En prisión, estableció contacto con Victoria Martínez y se benefició de las ayudas organizadas por las mujeres de preso y el MDM. A finales de los años sesenta, decidió viajar a Zaragoza y reunirse con las mujeres del Partido Comunista en Aragón.

Para el caso zaragozano, el MDM comenzó en casas particulares donde algunas familiares de presos políticos, compañeras de partido y amigas, empezaron a reunirse clandestinamente y a hablar de la situación de la mujer en el contexto de la Dictadura y de la situación de la mujer en el Partido. El objetivo fundamental era dar a conocer en Zaragoza la dura represión del Régimen y las malas condiciones de vida, unido a las torturas a los presos así como trabajar por acabar con la discriminación de la mujer. Para ello, llevaron a cabo recogidas de firmas, visitas al arzobispo de Zaragoza, al gobernador, al vicario, a diferentes párrocos, abogados..., se reunieron con los grupos de cristianos de base de la JOC (Juventud Obrera Católica) y con vecinos y vecinos del Barrio Oliver y Picarral. Sin embargo, no consiguieron infiltrarse en las asociaciones de amas de casa ni llegar a formar grupos en Huesca y Teruel, que eran dos de los objetivos fundamentales que se plantearon.

14 A las reivindicaciones de derechos y libertades, la denuncia de las torturas y la petición de amnistía se sumó la conciencia feminista. Una de sus iniciativas fue la celebración del 8 de marzo. Como conmemoración de esa fecha, en 1971, subieron regalos a las presas políticas de Torrero, realizaron charlas con algunas obreras de la fábrica Tudor y algunas católicas de la JOC con el objetivo de explicar lo ocurrido en 1908 y concienciar a la mujer de su discriminación laboral y social el día de la mujer trabajadora (Archivo Histórico del PCE, MDM, Caja 117 carpeta 2/3).

La actividad del MDM aragonés disminuye a partir de 1972, con la dura represión política desde el estado de excepción y debido a injerencias del Partido a nivel provincial que lastraron toda capacidad de movilización autónoma hasta el punto de que en 1973 les obligaron a disolver la organización. 


\section{Resistencias femeninas en la Zaragoza de los años setenta} diferentes contextos de lucha, así como en partidos políticos nuevos. El contexto en la fábrica, en los barrios o en la Universidad y los contactos personales condicionan la toma de contacto con estos partidos y se produce una mayor movilización que en la década anterior. Además, para muchas militantes, esta experiencia, la de tomar una posición contraria a lo establecido legalmente incluyó un empoderamiento personal contra la discriminación por cuestión de género impuesta estructuralmente por el Régimen, aprehendida socialmente, que impregnaba todos los ámbitos de la cotidianeidad. Por ello, lo que vemos en este apartado de nuevo es la necesidad de compaginar el activismo contra Franco con el feminismo. Las mujeres activistas configuraron un sujeto político propio que debía conciliar luchar contra el franquismo con una revolución personal, denunciando así la discriminación a la que les sometía el sistema por ser mujeres.

Además del PCE, otros partidos políticos tuvieron un papel relevante en los años setenta frente a la Dictadura. Estos se situaban a la izquierda del comunismo y fueron los llamados partidos de la izquierda radical. Basculaban ideológicamente desde el marxismo leninismo al trotskismo y el maoísmo. Sus objetivos eran acabar con la Dictadura y hacer la «revolución», con diferentes estrategias según la ideología. Todos abogaban por la ruptura con el franquismo desde la crítica al capitalismo. el Partido del Trabajo de España PTE, la Organización Revolucionaria de Trabajadores ORT, la Liga Comunista Revolucionaria LCR y la Larga Marcha hacia la Revolución Socialista ${ }^{5}$.

Defendían la amnistía para los presos y la Libertad, a la par que luchaban por huir de la represión de la dictadura y conseguir una democracia obrera, dándole la palabra a la clase trabajadora ${ }^{6}$. En ellos se configuró un nuevo arquetipo femenino, «la militante», en el que se englobaron, como representantes del mismo, un perfil muy variado de activistas: estudiantes universitarias, trabajadoras, católicas de base, amas de casa... un heterogéneo grupo de mujeres, con similares experiencias, que deciden comprometerse políticamente contra Franco, que entendieron la militancia como una lucha necesaria por la «revolución», por la ruptura con el franquismo, por la justicia social, frente a la violencia y la impunidad del Régimen. Las historias de vida son parejas entre las militantes. Son hijas de la generación que vivió la Guerra Civil, herederas del contexto de desarrollismo y emigración de los años sesenta, muchas de ellas se trasladan de los pueblos de Aragón a la ciudad para acceder a unas mejores condiciones de vida.

Son trabajadoras y universitarias que aspiran a una transformación social, personal y política del mundo y del contexto propio profunda, con una crítica a las relaciones de género imperantes y con un rechazo al modelo de mujer impuesto preconizado en las figuras aprehendidas desde las propias familias. Muchas de ellas se adhieren al feminismo radical en la segunda mitad de los setenta. La figura de «la militante» lleva consigo un compromiso vivencial por la transformación de su propio contexto, desde la fábrica, desde la Universidad, desde el barrio... Por ello, igual que en el PCE, crearon dentro de los 
partidos de izquierda radical grupos específicos de mujeres que debían trabajar, desde la militancia revolucionaria, el feminismo.

Nosotros éramos pensamiento Mao Tse Tung, los pro chinos, y a mí lo que me gustó fue el estudio teórico del marxismo [...] el estudio de (Marta) Harnecker, de Lenin, de Marx, El Capital... y esto me gusto mucho y yo continué, porque esto también me abrió a las mujeres. A raíz de esto conocí a Alexandra Kollontai... y esto me hizo llevar a cabo otro planteamiento que luego me enfrentó a mis compañeros por la defensa de la igualdad. Todos estos partidos tenían una sección «de la mujer», «feminista» entre comillas y yo llevaba la de Aragón, llevaba la de la ORT y PT de Aragón y entonces me reunía con las de Madrid. [...] En las reuniones de células o de estudios teóricos nosotras siempre planteábamos alguna cosa de «feminismo» entre comillas. Luego empezamos a hacer acciones conjuntas desde celebrar el 8 de marzo, hacer alguna pancarta, sacar algún artículo en Cambio 16 y en los periódicos de los partidos empezamos a sacar también noticias alusivas, de cosas concretas, empezamos a reivindicar otra forma de sexualidad, la anticoncepción [...] (entrevista a Inmaculada Torres, pseudónimo) ${ }^{7}$.

Estos grupos específicos dentro de los partidos crearon una conciencia de liberación, a partir de lecturas de feminismo, a partir de contactos personales dentro del partido y a partir de la relación con los compañeros y con la sociedad, que sería la piedra angular del movimiento feminista español de segunda ola que tendrá su máxima expresión en la segunda mitad de los años setenta.

\section{Militantes en las esferas de la movilización contra Franco: el sindicalismo, el movimiento universitario y el movimiento vecinal}

La política desarrollista que se implementa en Zaragoza desde el año 1965 tiene como consecuencias la masificación en los suburbios de la ciudad de familias emigradas del campo aragonés y de otras partes de España. Durante esa década, y pese a la escasa visibilidad que da el Régimen al trabajo femenino, el acceso de éste al mercado laboral aumenta considerablemente. Al fin y al cabo, para las nuevas políticas económicas desarrollistas, de implementación industrial, las mujeres eran mano de obra dócil que accedían al trabajo sumergido, no regulado y sin cotización ni protección social, que mantenía, a bajo coste, buena parte de la producción de las fábricas. Además, después del matrimonio, muchas continuaron con la producción a través del trabajo a domicilio que en muchas ocasiones dejó de ser un mero apoyo al sueldo del marido y se convirtió en base fundamental para la supervivencia de las familias (Babiano, 2007).

Ante esta situación, la estrategia de los partidos políticos clandestinos frente a las políticas del Régimen fue presionar conjuntamente desde la clandestinidad e intentar copar, desde dentro, los espacios de asociacionismo que el sistema permitía, ocupando los puestos del Sindicato Vertical o infiltrándose en las asociaciones de vecinos de los barrios, permitidas gracias a la Ley de asociaciones de 1965. En el caso de Zaragoza, esta situación permitió que, desde finales de los sesenta, se sindicalizasen muchas trabajadoras y que, desde la fábrica, desde el puesto de trabajo, entrasen en contacto con los partidos clandestinos. La organización sindical más consistente fue Comisiones Obreras, CCOO, el sindicato por excelencia en los años setenta y que aglutinó a trabajadoras de diferentes sectores, del textil, del calzado, de la administración y la sanidad, mujeres que trabajaban 
en cadenas de montaje e incluso en la construcción y el metal, estos últimos sectores muy masculinizados ${ }^{8}$.

En 1975, las trabajadoras decidieron organizarse en secciones propias dentro del Sindicato con el objetivo de sacar a la luz las condiciones de discriminación laboral que sufrían las mujeres y conseguir mejoras en los convenios. Es el caso de Carmen, zaragozana, trabajadora en la Residencia Sanitaria José Antonio (hoy Hospital Miguel Servet) y militante de CCOO en los años setenta, que participó en las elecciones del sindicato vertical de 1975 y en la Secretaría de la mujer de CCOO. Como recuerda, las reivindicaciones pasaban por compaginar la lucha contra el franquismo con las peticiones específicas: igualdad salarial, huelgas contra las condiciones salariales miserables y contra los abusos de los patronos. Además, se debía hacer frente a una cierta condescendencia por parte del Sindicato.

Se decía que en todas las negociaciones tenía que estar la Secretaría de la mujer, que había que llevar unos puntos. Nunca te decían que no, pero luego lo primero que se caía era lo tuyo. Y bueno, no se asumía pero formalmente estábamos ahí. Y eso no quita que nosotras nos organizásemos [...] para estudiarnos los convenios, para proponer alternativas que fuesen relativamente reconocidas... en todos los convenios nuestros objetivos eran meter nuestras reivindicaciones concretas, para que se viera, y era muy difícil pero no porque fuese difícil teníamos que abandonar (entrevista a Carmen Peguero, pseudónimo, 2017).

La acción del sindicalismo se complementaba con la protesta universitaria. Desde los años sesenta, la Universidad de Zaragoza experimentó un notable aumento de la oposición al régimen y durante los años setenta el Comité de estudiantes revolucionarios de Zaragoza (CERZ) y el Comité de estudiantes (CCEE) ocuparon la acción contra la Dictadura en esta Universidad. La relación entre estos comités estaba en el impacto que supuso mayo del 68 y en la necesidad de organizarse contra Franco desde los partidos políticos clandestinos que se infiltraron en la Universidad'.

Entre 1972 a 1974 se suceden hechos de suma importancia para la movilización estudiantil. En 1972, las facultades de Ciencias, Filosofía y Derecho fueron escenarios de la huelga de estudiantes más importante en todos los años del tardofranquismo y de una manifestación que reunió a más dos mil personas. Sus peticiones pasaban por cambiar los estatutos que regían las universidades y también, contra el régimen, a través del paro y las asambleas, en sus propias palabras, para retar a la «universidad fascista». Los paros además tenían un fuerte componente cultural, acompañados de recitales de poesía, mú sica de cantautores como José Antonio Labordeta o el trabajo en seminarios paralelos a las clases. Año y medio después, en marzo de 1974, el asesinato de Salvador Puig Antich provocó en Zaragoza el paro total de la Universidad, su cierre durante dos días por orden del rector y una multitudinaria manifestación a la que le siguió una cruenta represión.

Muchas universitarias se sumaron a los comités. La militancia en el Partido, ser coherente con la ideología, comprometerse políticamente y estudiar a la vez, debían ser aspectos a compaginar. Pegar carteles, repartir propaganda en las aulas, hacer manifestaciones, sentadas... estudiar y a la vez hacer política contra Franco. Al igual que para sus compañeros, los paros de las clases, las asambleas, los recitales y las clases paralelas, la solidaridad con compañeros detenidos y procesados por su actividad estudiantil crearon una conciencia y una emoción colectiva contra el Régimen y por la «revolución». De igual forma, empezaron a ver y denunciar el machismo en las aulas pero también en los comités. El machismo de los profesores y en las asambleas donde todo se debatía pero apenas había universitarias ocupando la palabra. Desde esta posición trabajarían a través 
de lecturas y actos de protesta en las facultades el feminismo y después algunas militaron en las organizaciones feministas de la ciudad.

Por último, fruto de las políticas económicas y el acceso masificado a las fábricas, los estudiantes y obreros se instalaron en las zonas suburbiales de la ciudad. En los barrios de Casablanca, Picarral y Oliver crearon, a raíz de la Ley de asociaciones de 1965, las primeras Asociaciones de Cabezas de Familia. Estas asociaciones debían defender unas condiciones mínimas de salubridad en el barrio, una vivienda digna frente a la especulación del suelo, la denuncia de la segregación urbana de clase y el desamparo al que el Ayuntamiento les sometía. En este contexto y con el amparo del catolicismo de base, los partidos políticos clandestinos se infiltraron en las Asociaciones. Frente a la falta de derechos y libertades, este asociacionismo de barrio permitió cobijar las acciones contra el régimen desde un espacio de reunión legal que, en muchas ocasiones, fue amparado por los párrocos y las juventudes católicas que cedían sus espacios para realizar reuniones clandestinas, en contra de las políticas de la dictadura ${ }^{10}$.

En estas asociaciones se implicaron muchas obreras, estudiantes y también amas de casa, que conocían bien las carencias del barrio por ser el espacio habitual donde ellas trabajaban. Mientras muchos de sus maridos militaban contra Franco en el sindicato o en el partido, el asociacionismo vecinal tuvo especial relevancia para que muchas mujeres saliesen de sus casas. Como en los otros espacios analizados, decidieron compaginar las luchas del barrio con el feminismo, reuniéndose en grupos específicos para poder hablar así de situaciones de discriminación que les eran comunes.

En el Picarral se creó la primera vocalía de la mujer, a la que posteriormente le siguieron otros barrios. Las actividades de estas vocalías tenían como objetivo empoderar a las mujeres del barrio, darles la oportunidad de salir de casa, de hablar de su situación personal y compartir además problemas que les eran comunes. Desde el año 1971, las integrantes del MDM intentaron, desde este enclave, concienciar políticamente al resto de mujeres y hacerles conocedoras de su opresión específica. Para ello, se llevaron a cabo charlas sobre la carestía de vida, el uso de anticonceptivos, el placer sexual y el aborto, y llevaron a cabo actividades de empoderamiento personal. Gracias a las integrantes del movimiento vecinal, los barrios se convirtieron en un enclave de politización crucial, el cual posibilitó la gran transformación de los roles de género que vivió la sociedad española durante los años setenta.

\section{Conclusiones}

31 A lo largo de estas páginas, he intentado hacer una aproximación a los diferentes espacios en los que se articularon resistencias femeninas contra el franquismo en la ciudad de Zaragoza entre 1965 y 1975. Zaragoza es una ciudad paradigmática de la represión y del desarrollismo industrial en el Estado español y estos aspectos propiciaron una conflictividad laboral, estudiantil y vecinal muy importante.

Como hemos visto, estas resistencias son una respuesta a la ideología y al modelo de género de la Dictadura. Durante los años sesenta, el PCE fue el partido que luchó contra Franco. Las mujeres del PCE fueron represaliadas por el Régimen y estigmatizadas por ser mujeres comunistas. Muchas trabajaron para mejorar la situación de sus familiares presos $\mathrm{y}$, desde la clandestinidad, realizaron acciones reivindicando la reconciliación nacional y la amnistía. Además, crearon la primera organización feminista desde la Guerra Civil y se 
trasladaron a otros ámbitos como las fábricas o los barrios periféricos para concienciar a otras mujeres de su situación de desigualdad.

En los años setenta asistimos a múltiples contextos en los que las reivindicaciones contra el régimen adquieren mayor protagonismo. La militancia contra Franco en los partidos y sindicatos clandestinos, en la universidad o las resistencias desde la vida cotidiana en los barrios fueron vías de acceso a una conciencia crítica con el franquismo. Ante el estado de necesidad de los barrios periféricos que el desarrollismo industrial dejaba, el defender un salario, una vivienda y un barrio digno se convirtieron en reivindicaciones ciudadanas contra la Dictadura. En estos enclaves encontramos la figura de la militante, un arquetipo que engloba a mujeres herederas del desarrollismo, hijas de la generación que vivió la Guerra Civil, mujeres jóvenes, comprometidas políticamente, que participaron en las movilizaciones contra Franco desde su contexto personal y desde éste precisamente adquirieron conciencia de su doble explotación.

Frente a la desigualdad de género impuesta y frente al desinterés de los propios partidos en sus reivindicaciones, que en muchas ocasiones seguían viendo a sus compañeras como esposas y madres, estas militantes decidieron organizarse de forma paralela en grupos específicos de trabajo. Fueron conscientes de que para hacer la revolución, la transformación social debía ir acompañada de la transformación personal y estos grupos fueron la semilla que enraizó en la segunda mitad de los setenta con el movimiento feminista de segunda ola en Aragón.

\section{BIBLIOGRAFÍA}

ABAD Irene (2008), «El papel de las “mujeres de preso” en la campaña pro amnistía», Entelequia, 7, 139-151.

ABAD Irene (2012), En las puertas de prisión. De la solidaridad a la concienciación política de las mujeres de los presos, Barcelona: Icaria Editorial.

ARRIERo Francisco (2016), El Movimiento Democrático de Mujeres: de la lucha contra Franco al feminismo (1965-1985), Madrid: Catarata.

BABIANO José (2007), Del hogar a la huelga: trabajo, género y movimiento obrero durante el franquismo, Madrid: Catarata.

Bella Amparo (2003), «La lucha por la amnistía y el Movimiento Democrático de Mujeres Zaragoza, 1960-1976», P. Rújula \& I. Peiro (dir.), En Construcción. Historia Local contemporánea, Daroca: Centro de estudios darocenses.

BLASCO Sandra (2016), «La voz atada [al yermo del paisaje y a la sangre en flor]: Dolor, resistencia y ternura en los recuerdos de José Antonio Labordeta a través de su poemario y cancionero», Rolde, 158-159, 49-65.

CABRERA Miguel Ángel (2001), Historia, lenguaje y teoría de la sociedad, Madrid: Cátedra.

CABRERO Claudia (2016), Mujeres y antifranquismo en Asturias (1957-1975). Una resistencia en femenino plural (tesis doctoral), Universidad de Oviedo, Oviedo. 
Di FEBo Giuliana (1979), Resistencia y movimiento de Mujeres en España 1936-1976, Barcelona: Icaria.

FERNÁNDEZ Eva (2009), Vocalies de Dones de Barcelona a la Transició Democràtica: una experiència emancipadora, Barcelona: Universidad Autónoma de Barcelona.

MIR Conxita (2001), «La represión bajo el franquismo», Ayer, 41, 11-35.

MORENo Amparo (1977), Mujeres en lucha. El movimiento feminista en España, Madrid: Anagrama.

NASH Mary (1994), «Experiencia y aprendizaje: la formación histórica de los feminismos en España», Historia social, 20, 151-172.

ORTEGA Javier (1999), Los años de la ilusión. Protagonistas de la transición, Zaragoza, 1973-1983, Zaragoza: Mira.

PÀmIEs Teresa (1975), Dona de pres, Barcelona: Proa.

PORTUONDO Ernesto (1994), «Forja de rebeldes. Una aproximación a los orígenes de las vanguardias militantes del radicalismo de izquierdas en la segunda mitad de los sesenta: el movimiento estudiantil (1964-1970)», J. M. Roca (dir.), El proyecto radical. Auge y declive de la izquierda revolucionaria en España (1964-1992), Madrid: Libros de la Catarata.

RoMEU Fernanda (1994), El silencio roto. Mujeres contra el franquismo, Madrid: F. R. Alfaro.

RUIZ CANRICER Miguel Ángel (1993), «Dictadura y Desarrollo, 1956-65», C. Forcadell (coord.), Historia contemporánea de Aragón, Zaragoza: Heraldo de Aragón, 339-360.

RuIz GonZÁLEz David (1994), Historia de Comisiones Obreras (1958-1988), Madrid: Siglo XXI.

Sсотт Joan (1986), «El género: una categoría útil para el análisis histórico», J. Amelang \& M. Nash (dir.), Historia y género, 23-58.

ScoTt Joan (2008), «Revisiting “Gender: A Useful Category of Historical Analysis”», American Historical Review, 113, 1422-1443.

YUSTA Mercedes (2005), «Mujeres en la resistencia antifranquista: Un estado de la cuestión», Arenal, 12, 5-34.

WILHELMI Gonzalo (2016), Romper el consenso. La izquierda radical en la transición española (1975-1982), Madrid: Siglo XXI.

\section{NOTAS}

1. Militante del Partido Comunista en Zaragoza. Hermana de Manolo Gil, militante comunista y dirigente de CCOO en la clandestinidad.

2. Secretaria General del MDM en Zaragoza. Hermana de Vicente Cazcarra (responsable del PCE en Aragón). Maruja visitaba a su hermano en la cárcel Modelo de Barcelona y allí conoció a otras hermanas, madres y esposas de obreros del cinturón de Barcelona condenados por secundar una huelga en 1962. Su actividad posteriormente se basó en conseguir mejoras para las condiciones de los presos políticos en la penal de Burgos y, finalmente, con el traslado de Vicente a Zaragoza, fundó en esta ciudad el MDM aragonés.

3. Militante obrera y sindical, juzgada y encarcelada en 1937 por «auxilio a la rebelión». Esposa de Antonio Rosel, preso político por intentar reorganizar clandestinamente el PCE en Zaragoza en 1958.

4. Militante comunista y antifranquista. Participó activamente en la lucha contra Franco y en la solidaridad con los presos políticos. Militante feminista en el MDM en los años sesenta y 
posteriormente militante en la organización Unión de Mujeres por su liberación (UML) a finales de los años setenta.

5. El MC era un partido marxista revolucionario, abandono el maoísmo en 1976. En Huesca y Zaragoza, muchas mujeres del MC abrazaron la revolución social y el feminismo. Tenía una organización de mujeres dentro del partido y tuvo gran arraigo en Aragón, sobre todo, en los comités de estudiantes de letras y en algunos barrios. El PTE era maoísta en sus documentos aunque, según Gonzalo Wilhelmi, estaba ideológicamente cerca del estalinismo y mantuvo contactos con el Partido Comunista Rumano de Ceauçescu. La estrategia maoísta funcionaba fundamentalmente para diferenciarse del PCE. Crearon una organización de mujeres, la ADM, que tuvo importancia en Zaragoza. La ORT tenía orígenes cristianos y se inspiraban en el maoísmo. Su implantación estuvo fundamentalmente en las fábricas. La LCR era un partido trotskista, con implantación en la universidad y algunos barrios, que mantuvo su actividad hasta finales de los años ochenta, fusionándose con el MC. La Larga Marcha hacia la Revolución Socialista fue un partido de tendencia maoísta creado originariamente en Zaragoza. Tuvo importancia en el comité de estudiantes de ciencias y en algunos barrios de la ciudad.

6. La Libertad con mayúscula hace referencia a la emoción de los militantes en los años setenta ante las posibilidades que les abría el final el franquismo. La llegada de ese marco político tantas veces soñado, frente al miedo y la represión, «el momento de poder tomar una posición, de dar la palabra al pueblo vencido, la sensación de vivir en los límites de lo posible y de lo imposible» (Blasco, 2016).

7. Inmaculada era militante del PTE y vecina del barrio de San José, en el cuál participo activamente a través del Comité de barrio. Su experiencia dentro de la militancia antifranquista le llevó a desarrollar una conciencia de clase y, a la par, una conciencia feminista. En 1976 organizaría junto a otras compañeras la primera organización feminista, independiente de los partidos políticos, en Aragón, la Asociación Democrática de la Mujer Aragonesa (ADMA). Entrevista realizada el 7 de marzo de 2017 en el Café Levante de Zaragoza.

8. La historia de CCOO en Zaragoza se remonta a finales de los años cincuenta, a trabajadores con una tradición política sindicalista, una tradición que podemos vincular al sindicalismo de la CNT de los años veinte y treinta, y que en torno a 1958 y hasta 1966, cuando se crea el grupo aragonés de CCOO, empiezan a realizar las primeras huelgas para mejorar sus condiciones de trabajo. Un primer grupo que apenas deja testimonios escritos. El crecimiento industrial, la emigración joven del campo a la ciudad y el aumento del obrerismo zaragozano en los años sesenta permiten que en las elecciones sindicales de 1966 se organicen reuniones de obreros del metal y de la construcción, en conexión con la HOAC y las JOC, para plantear candidaturas alternativas al Sindicato vertical. El objetivo es destruir el sindicato desde dentro y además realizar acciones ilegales fuera. A finales de los años sesenta, la capacidad de movilización ha aumentado de forma extraordinaria y, tras el estado de excepción de 1969, lo sindical y lo político, los derechos laborales, la libertad y la amnistía, se unifican y es el PCE quien asume como propia la capacidad del sindicalismo para acabar con la Dictadura (Ruiz Gonzalez, 1994).

9. Durante los años sesenta, las resistencias al régimen desde el ámbito universitario fueron llevadas a cabo por el PCE. Sobre todo desde la desaparición del SEU, sindicato falangista, en 1965. A finales de los sesenta y principios de los setenta también tuvo protagonismo la FUDE (Federación Universitaria Democrática Española) y, sobre todo, desde mayo del 68 y las implicaciones de aperturismo que tuvo para el ámbito universitario, la oposición al Régimen se desmigaja en numerosos colectivos universitarios que se sitúan en su mayoría a la izquierda del PCE. La muerte de un estudiante en Madrid a manos de la policía en 1968, desencadenó una manifestación de más de 10000 personas por el centro de Zaragoza. En los años setenta, el CERZ y los CCEE fueron los organismos fundamentales de protesta. Aunque mayoritariamente eran del MCE y la Larga Marcha, en el CERZ también había de la ORT, de Acción Comunista e independientes (Ruiz Carnicer, 1993: 339-360; Portuondo, 1994). 
10. En los años sesenta, dos hechos fundamentales hacen posible la fractura de la base eclesial con la Iglesia institucional del franquismo. En primer lugar, el impacto del Concilio Vaticano II que propugna una revisión de los preceptos del cristianismo, una apertura social y una relación entre la fe y el compromiso social y político. En segundo lugar, el plan de estabilización y el desarrollismo, que aglutinó a un incipiente obrerismo en las fábricas y en los barrios periféricos de las grandes ciudades en unas pésimas condiciones de vida. Estas dos circunstancias hicieron que Acción Católica pasase del compromiso con los más desfavorecidos y la evangelización a un compromiso político, obrero, sindical, vecinal contra el Régimen. En relación al Concilio Vaticano II, Zaragoza tuvo su punto de inflexión en el impacto del Caso Fabara.

\section{RESÚMENES}

Este artículo analiza las resistencias femeninas del tardofranquismo en una ciudad paradigmática del desarrollismo y la represión franquista como es Zaragoza.

Los barrios, la universidad, los grupos católicos de base, las fábricas y los partidos y sindicatos clandestinos fueron espacios «desde abajo» que abrieron grietas en la Dictadura de Franco gracias a la organización popular y a la movilización en las calles, donde la participación femenina frente a la dictadura tuvo una considerable relevancia para el progresivo desmantelamiento del régimen, así como para la transformación de las relaciones de género.

The aim of this paper is to analyze feminine resistances at the end of the Francoism in Zaragoza, a paradigmatic city regarding economic development and francoist repression.

The neighborhoods, the university, the Catholic groups, factories and clandestine parties and unions were spaces "from below" that cracked the Regime thanks to popular organization and enormous street mobilizations, where women's participation had relevance.

Cet article analyse les résistances des femmes de l'époque dite du «franquisme tardif » dans une ville-modèle du développement et de la répression franquiste comme l'est Saragosse. Les quartiers, l'université, les groupes catholiques de base, les usines, les partis politiques et les syndicats clandestins furent des espaces «d'en bas" qui fissurèrent le régime grâce à l'organisation populaire et à la mobilisation dans les rues où la participation féminine contre la dictature eut une grande importance.

\section{ÍNDICE}

Mots-clés: résistances féminines, répression, gauche radicale, antifranquisme, Saragosse

Palabras claves: resistencias femeninas, represión, izquierda radical, antifranquismo, Zaragoza

Keywords: feminine resistances, repression, radical left, antifrancoism, Zaragoza 


\section{AUTOR}

\section{SANDRA BLASCO LISA}

Sandra Blasco Lisa: Licenciada en Historia y graduada en Ciencias Políticas y de la Administración. Máster en Historia Contemporánea. Contratada pre doctoral en el Departamento de Historia Moderna y Contemporánea de la Universidad de Zaragoza.

Temas de investigación: Feminismos en los años setenta y ochenta en España. Pacifismo feminista en España en el periodo de entreguerras y sus conexiones con la Women's International League for Peace and Freedom (1914-1945).

sanblasco@hotmail.es 